\title{
Ecosystem impacts of marine heat waves in the Northeast Pacific
}

\author{
Abigale M. Wyatt ${ }^{1}$, Laure Resplandy ${ }^{1,2}$, Adrian Marchetti ${ }^{3}$ \\ ${ }^{1}$ Department of Geosciences, Princeton University, Princeton, NJ, USA \\ ${ }^{2}$ High Meadow Environmental Institute, Princeton University, Princeton, NJ, USA \\ $5 \quad{ }^{3}$ Earth, Marine and Environmental Sciences, University of North Carolina, Chapel Hill, NC, USA \\ Correspondence to: Abigale Wyatt, awyatt@princeton.edu
}

\begin{abstract}
Marine heatwaves (MHWs) are a recurrent phenomenon in the Northeast Pacific that impact regional ecosystems and are expected to intensify in the future. These events, including the 2014-2015 "warm blob," are associated with widespread surface nutrient declines across the subpolar Alaskan Gyre (AG) extending south into the North Pacific Transition Zone (NPTZ) with reduced chlorophyll concentrations confined to the NPTZ only. Here we explain the contrast between these two regions using a coupled global ocean-biogeochemical model (MOM6COBALT) with Argo float and ship-based observations to investigate how the MHWs influence the productivity of the two primary phytoplankton size classes (large $>10 \mu \mathrm{m}$, small $<10 \mu \mathrm{m}$ ) and the subsequent ecosystem response. Differences in seasonal iron and nitrate limitations between the AG and NPTZ explain the differences in ecosystem response to MHWs between the two biomes. The reduced nutrient supply during MHWs most strongly influences large phytoplankton in the NPTZ (-13\% annually), whereas it has a limited impact on the climatologically iron-limited large phytoplankton population in the AG (-2\%). Contrastingly, we find that MHWs yield a springtime increase in small phytoplankton population in both regions due to shallow mixed layers and lower light limitation. These primary production anomalies modify the allometric phytoplankton distribution, resulting in a $2 \%$ decrease in the ratio of large to small phytoplankton in both regions. This shift in the assemblage towards small phytoplankton production is associated with reduced secondary and export production, especially in the NPTZ.
\end{abstract}

\section{Introduction}

Marine heat waves (MHW) are a recurring phenomenon in the Northeast Pacific, with nine events recorded since 1958 (Xu et al. 2021). The largest such event, which occurred during the satellite chlorophyll (Chl) era, was a persistent marine heat wave known as the "warm blob" that appeared in the Northeast Pacific in 2014 and 2015 and was characterized by a greater than $2^{\circ} \mathrm{C}$ surface temperature anomaly in the Northeast Pacific (Freeland and Whitney 2014; Bond et al. 2015; Di Lorenzo and Mantua 2016). The 2014-2015 marine heat wave broadly influenced ecosystems in the northeast Pacific Ocean, with for instance, a redistribution of marine biogeography, and anomalous appearances of fish species outside of their known geographical range across the northeast Pacific (See Bond et al. 2015) with some such effects persistent and/or permanent (Suryan et al. 2021). In situ observations indicate that the warm blob particularly affected ecosystems in two regions: the subpolar Alaskan Gyre (AG) and the Northeast Pacific Transition Zone (NPTZ roughly between $30^{\circ} \mathrm{N}$ to $45^{\circ} \mathrm{N}$ ), i.e. the region of strong Chlrophyll and nitrate gradient that demarks the boundary between the AG and the eastern subtropical Pacific gyre. Major impacts of this warm blob 
included a $\sim 35 \%$ decrease in satellite surface Chlrophyll in the NPTZ (Whitney et al. 2015), as well as a reduction in nitrate surface concentrations and phytoplankton biomass, and an increase in cyanobacteria dominance along the subarctic transect Line P which samples both the NPTZ and AG regions (near 50 N, Peña et al. 2019). Further, estimates of net primary productivity suggested there was an ecosystem collapse in the second year of the warm event near Ocean Station Papa in the AG (OSP, $50.1^{\circ} \mathrm{N}, 144.9^{\circ} \mathrm{W}$, Bif et al. 2019b), despite a lack of satellite surface Chl anomaly in this region.

Prior work offered a bottom-up explanation for the Chl anomalies observed in the NPTZ during MHW, noting that the 2014-2015 heat wave was associated with decreased winds that reduced nitrate concentrations and inhibited primary production (Whitney 2015). This bottom-up explanation does not explain why the decrease in Chl was highly localized, confined to the NPTZ, while anomalously low nitrate concentrations extended into the AG, $600 \mathrm{~km}$ north of any significant $\mathrm{Chl}$ anomalies (Peña et al. 2019). In addition, surface Chl alone provides little information on food web changes beyond primary production and how marine heat waves influence secondary production and marine biogeography. Finally, it is unclear to what extent the observed anomalies in nitrate and Chl are unique to the "warm blob" or typical of the MHWs in this area.

The AG and NPTZ are distinct ecological biomes. The AG is a high nutrient, low Chl (HNLC) region, characterized by high nitrate concentrations, but moderate primary production throughout the year due to iron limitation that prevents the development of a strong spring bloom (Martin and Fitzwater 1988; Harrison 2002; Boyd et al. 2004, Peña and Varela 2007). In contrast, the NPTZ is a region characterized by strong seasonality in nitrate and Chl due to the seasonal biological consumption and the Ekman-driven transport of nutrients (Polovina et al. 2008, Chai et al. 2003; Ayers and Lozier 2010). As a result, the NPTZ evolves from a subpolar-like, iron-limited biome in spring to a nitratedepleted, subtropical-like biome in summer, with the position of the Chl front associated with the bloom $\left(2 \mathrm{mg} \mathrm{m}^{-3}\right.$ Chl contour) shifting $\sim 10^{\circ}$ northward in summer from its southernmost position in winter $\left(30^{\circ}\right.$ to $40^{\circ} \mathrm{N}$, Bograd, et al. 2004).

In this study, we examine the ecosystem response to the nine MHWs that were recorded since 1958 in the AG and NPTZ biomes. Using a combination of observations and ocean biophysical model results, we first characterize MHWs in section 3.1. Then in section 3.2, we examine the extent of nitrate depletion during MHWs and show that the boundary between the subpolar HNLC region and the NPTZ shifts during these events, expanding the region of nitrate depletion. We then analyze the biological response to MHWs in the NPTZ and the contrasted response in the AG (sections 3.3 and 3.4), with particular emphasis on the responses of the two phytoplankton size classes. Our results indicate that during MHWs, though the Chl anomaly is confined to the NPTZ, both regions exhibit a shift in the phytoplankton assemblage toward the smaller size class, resulting in the reduction of secondary and export production. 


\section{Methods and datasets}

\subsection{Definition of northeast Pacific marine heatwaves}

Following the method of Xu et al. 2021, we calculate sea surface temperature anomalies (SSTa) in the region from $35^{\circ}$ to $46^{\circ} \mathrm{N}, 150^{\circ}$ to $135^{\circ} \mathrm{W}$ using the monthly Extended Reconstruction SST dataset (ERSSTv4, Huang et al., 2015). Northeast Pacific marine heatwaves are selected by taking the anomalies that exceed 1 standard deviation for 5 months or more. The same method is used to detect marine heatwaves in the ocean model (see Sect. 2.3 for model details). We define heatwaves considering their impact on the spring-summer blooming season. For example, what we refer to as the "year 1990 heatwave" started in November 1989 and ended in March 1990, thus impacting the ecosystem in 1990. In both ERSST and the model, the "marine heatwaves" or "warm years" selected using these criteria are 1962, 1963, 1965, 1990, 1991, 2005, 2014, 2015 and 2019 similar to what was found by Xu and coauthors (Fig. 1). We compute the composite of these nine events to evaluate the impact of heatwaves. Composite anomalies are compared across two subregions representative of the NPTZ ( $39^{\circ}$ to $45^{\circ} \mathrm{N}$ and $160^{\circ}$ to $135^{\circ} \mathrm{W}$ ) and the HNLC Alaskan Gyre ( $48^{\circ}$ to $54^{\circ} \mathrm{N}$ and $160^{\circ}$ to $145^{\circ} \mathrm{W}$, see Fig. 6).

\subsection{Line $P$ data processing}

We use Line $\mathrm{P}$ observations of temperature, salinity, nitrate and Chl a available online (downloaded from www.waterproperties.ca/linep on Mar 19, 2021). Data from the two summertime cruises, May \& June and Aug/Sep, were averaged at each of the 26 stations from 2007 to 2020. The Jan/Feb cruise data were not used as we focused on the period of seasonal nitrate depletion. Notably there is no Chl data available for 2008 to 2010 . For comparison, the model results were sampled at the same station locations, averaged across June, July and August each year to obtain a summer mean.

95

\subsection{Ocean biogeochemical model (MOM6-COBALT)}

This study uses the biophysical ocean model described in Liao et al. 2020. This model configuration uses the fourth generation global ocean/sea ice model OM4p5 developed at the Geophysical Fluid Dynamics Laboratory, consisting of the Modular Ocean Model version 6 (MOM6) and the Sea Ice Simulator version 2 (SIS2, Adcroft et al. 2019). The physical ocean circulation model has a nominal $0.5^{\circ}$ x $0.5^{\circ}$ resolution in the horizontal and 75 hybrid depth-isopycnal $\mathrm{z}^{*}$ layers in the vertical. The physical model is coupled with the biogeochemical model Carbon, Ocean Biogeochemistry and Lower Tropics v.2 (COBALTv.2) that simulates a nitrogen-based ecosystem with 33 biochemical tracers and 13 food web components (Stock et al 2014, 2020). These components include three 105 phytoplankton size classes: large $(>10 \mu \mathrm{m})$, small $(<10 \mu \mathrm{m})$, and nitrogen-fixing diazotrophs; three zooplankton size classes of which large ( $>2000 \mu \mathrm{m})$ and medium (200 to $2000 \mu \mathrm{m})$ make up the mesozooplankton pool and the third is a separate small zooplankton class $(<200 \mu \mathrm{m})$. These nitrogen-based tracers are assumed to maintain a stoichiometric 
relationship with carbon in accordance with the Redfield ratio, 106C:16N. Chl is calculated from phytoplankton biomass using a Chl:C ratio that depends on ambient light, temperature, iron availability and size-class specific nutrient limitation and maximum photosynthetic rates (Geider et al. 1997; Stock et al. 2014, 2020).

The model was spun-up using three repetitions of the 1958 to 1985 Japanese atmospheric reanalysis v1.4 (JRA55do v1.4, Tsujino et al. 2018) for a total of 81 years. Nutrient initialization comes from the 2013 World Ocean Atlas (WOA, Boyer et al. 2013) concentrations, while dissolved inorganic carbon (DIC) and alkalinity are from the global ocean data analysis project v2 climatologies (GLODAPv2, Olsen et al. 2016) with DIC corrected to 1958 using anthropogenic carbon concentrations from Khatiwala et al. (2013). Initial states of the remaining tracers (e.g. Chl, biomass, etc) were taken from a long, preindustrial control run from the GFDL Earth system model ESM2M-COBALT (Dunne et al. 2012). The model was then run from 1958 to 2019 using the JRA v1.4 forcing and river nutrient fluxes taken from the Global NEWS climatology (Seitzinger et al. 2010).

\subsection{Size-fractionated Chl $a$ concentration at OSP}

Discrete summertime measurements of mixed layer, size-fractionated $\mathrm{Chl} a(\mathrm{Chl} a)$ concentrations at OSP were obtained through collection of $300 \mathrm{~mL}$ of seawater from a Rosette system during Line P cruises in June of 2000, 2001, 2008, 2013, 2015 and 2018. The 2015 sample was taken during the "warm blob," while the 2013 sample was collected following the Mt. Pavlof eruption. Seawater was vacuum filtered through a $5 \mu \mathrm{m}$ pore-sized polycarbonate filter, and the filtrate was re-passed through a GF/F filter $(0.7 \mu \mathrm{m}$ nominal porosity $)$ set up in series. Filters were frozen at $-80^{\circ}$ $\mathrm{C}$ until analysis. Chl $a$ extraction was performed using $90 \%$ acetone or ethanol (2018) at $-20^{\circ} \mathrm{C}$ overnight and concentrations were determined fluorometrically using a Turner Designs 10-AU fluorometer (Brand et al. 1981).

130 Phytoplankton in the study regions are classified into two allometric classes. Small phytoplankton $(<5 \mu \mathrm{m}$ vs. $<10$ $\mu \mathrm{m}$ in model), primarily made up of cyanobacteria (e.g. Synechococcus) and nanoflagellates such as chlorophytes and haptophytes, comprise the majority of the biomass in both regions (Boyd and Harrison 1999) and are efficient nutrient and light harvesters (Munk and Riley 1952; Geider et al. 1997). Large phytoplankton ( $>5 \mu \mathrm{m}$ vs. $>10 \mu \mathrm{m}$ in model), primarily made up of dinoflagellates and diatoms, have a stronger correlation to particulate export production (Buesseler 1998), are subject to iron limitation inside the AG.

\subsection{Argo floats \& other datasets}

This study makes use of the 2008-2018 series of bioArgo floats deployed near OSP (e.g., Fig. 9). Specifically, we replicated the analyses of Plant et al. 2016 as updated in Bif et al. 2019a to evaluate net community production (NCP) from bioArgo float nitrate data then compare NCP estimates derived from nitrate concentrations in the WOA climatology and the MOM6-COBALT model. Following the quality control analyses of those studies, selected profiles from floats 5903405, 5903891 and 5903714 were dropped due to inconsistencies in the nitrate data (See Bif and Hansell 2019a). 


\section{Results}

3.1 Characterizing marine heat waves in observations and MOM6-COBALT ocean model

Marine heat waves show systematically high SST over a relatively broad area of the northeast Pacific that extends from $35^{\circ} \mathrm{N}$ to $55^{\circ} \mathrm{N}$ and from $170^{\circ} \mathrm{E}$ to the North American coast in both observations and the MOM6-COBALT model (up to $+1^{\circ} \mathrm{C}$ in average across the nine events, Fig. 1c,d). Surface Chl, in contrast, exhibits more spatial heterogeneity, with a strong decline in the NPTZ $\left(-0.05 \mathrm{mg} \mathrm{m}^{-3}\right)$ and a mild increase further north in the AG $(+0.02$ $\mathrm{mg} \mathrm{m} \mathrm{m}^{-3}$ around station OSP, Fig. 1e \& f).

We use the observations from 6 Argo floats that sampled the AG region around OSP between the years 2008 and 2019 to characterize interannual variability in the region (Fig. 2). These data show the strong signal associated with the 2014-2015 warm event, colloquially termed the "warm blob", including summer surface temperatures above $15^{\circ} \mathrm{C}$ and surface nitrate concentrations below $6 \mathrm{mmol} \mathrm{kg}^{-1}$ (Fig. $3 \mathrm{a}-\mathrm{c}$ ). Using the ocean model sampled along the floats trajectories yields similar features, with modeled temperatures exceeding $14^{\circ} \mathrm{C}$ and nitrate concentrations dropping to $<3 \mathrm{mmol} \mathrm{kg}^{-1}$ during the warm blob period (Fig. $3 \mathrm{~d}-\mathrm{f}$ ). It is worth noting that in both the observed and modeled profiles, large changes in temperature, nitrate and to a lesser extent salinity are apparent at depth $(>100 \mathrm{~m})$ in early 2015. The subsurface changes sampled by a single float (\#5904125, brown, Fig. 2) likely indicate sampling of a different water mass with a shallower thermocline and nutricline, in this case the inner AG (See Sect. 4.2). Regardless, these data support the bottom-up explanation of Whitney (2015). which posited reduced surface nitrate concentrations as a driver of reduced primary production and Chl concentrations during the "warm blob".

We can further observe this impact of the 2014-2015 marine heat wave on nitrate and Chl concentrations using 20072020 summer cruise data (June - September) from the Canadian Line P program, which sampled from the coast of British Columbia to OSP (yellow dots, Fig. 1). Fig. 4 shows a strong signal during the 2014-2015 "warm blob" along Line P, characterized by higher SSTs $\left(+2.5^{\circ} \mathrm{C}\right)$ and lower SSS $(\sim 0.2 \mathrm{PSU})$ between $130^{\circ} \mathrm{W}$ and $140^{\circ} \mathrm{W}$ (Fig. 4). During this period, observed $\mathrm{Chl}$ data reached concentrations below $0.3 \mathrm{mg} \mathrm{m}^{-3}$ (Fig. $4 \mathrm{~g}$ ) while nitrate concentrations are near-zero for most stations (P4-P20). We sampled the model results at Line P stations and found similar results, including SST $\left(+2^{\circ} \mathrm{C}\right)$ and salinity (-0.1 PSU) anomalies during the "warm blob", and despite a climatological model bias toward lower surface nitrate in this region (Fig. 2), the nitrate anomaly associated with the marine heat wave is still well simulated ( $-2 \mu \mathrm{M}$, Fig. X). The observed Chl anomaly is difficult to characterize due to a lack of data prior to 2011, however, the simulated $\mathrm{Chl}$ in the model strongly suggests a decline $\left(<0.3 \mathrm{mg} \mathrm{m}^{-3}\right)$ during the 2014-2015 period, consistent with the satellite observations (Fig. 1).

\subsection{Northward expansion of nitrate-depleted region in response to marine heatwaves}


The northeast Pacific is characterized by three regions: the nitrate-rich HNLC AG, the nitrate-depleted subtropical gyre, and the NPTZ region in between. Climatologically, WOA observations show that in winter, the nitrate-depleted region (identified here with surface $\mathrm{NO}_{3}<2 \mu \mathrm{M}$ ) extends from $\sim 35^{\circ} \mathrm{N}$ on the western side of the region to $\sim 45^{\circ} \mathrm{N}$ in the east near the North American coast (Fig. 5a, blue line). By the end of summer (September, green line), biological consumption has expanded the nitrate-depleted region, shifting the $2 \mu \mathrm{M}$ contour by about 2 to $5^{\circ}$ northward between $180^{\circ}$ and $140^{\circ} \mathrm{W}$ and by about $10^{\circ}$ east of $135^{\circ} \mathrm{W}$ and along the American coast. This seasonal displacement of the nitrate front is also captured in the MOM6-COBALT climatology, with an $\sim 8^{\circ}$ northward shift in the western region and a similar $10^{\circ}$ northward shift along the American coast (Fig. 5b). The large-scale north-south nitrate gradient is, however, more intense in the model, with an approximately $-2 \mu \mathrm{M}$ annual mean nitrate bias in the transition zone and $\mathrm{a}+2 \mu \mathrm{M}$ bias in the northwest Alaskan gyre (Fig. S1). Here we combine in situ observations with the results of the MOM6-COBALT ocean biophysical model and show that these warm events also systematically expand the spatial extent of nitrate depletion northward.

Using the modeled composite of the nine warm events (1962, 1963, 1965, 1990, 1991, 2005, 2014, 2015, 2019), we find that there is an intrusion of the nitrate-depleted region from the south into the NPTZ during warm events (Fig. 5b). Compared to the climatological $2 \mu \mathrm{M}$ nitrate boundary (solid lines), the $2 \mu \mathrm{M}$ nitrate boundary during marine heatwaves (thick dashed line) is located $\sim 2^{\circ}$ further north in February and $\sim 1^{\circ}$ north in September (Fig. 5b), and the model suggests that the nitrate boundary shift is greatest in the NPTZ. The WOA does not provide interannual information that we can use to evaluate the response to marine heat waves, but we can use observations from the sampling program at Line P (yellow dots), which intersects the $2 \mu \mathrm{M}$ nitrate boundary (i.e. transition between the nitrate-depleted and the nitrate-replete regions) in summer to examine its response to the 2014-2015 event.

The Line P program's June and August cruises sample three regimes (Fig. 4): the high-nitrate near-shore region $(>10$ $\mu \mathrm{M}$ at $\sim 125^{\circ} \mathrm{W}$ ), followed by the depleted nitrate region that extends to roughly $130^{\circ} \mathrm{W}$, before reaching the third region characterized by moderate to high nitrate values $(>5 \mu \mathrm{M})$ in the iron-limited Alaskan gyre. Observations show that the high nitrate concentrations along the coast and in the Alaskan gyre are co-located with colder sea surface temperatures ( $\mathrm{SST}<12^{\circ} \mathrm{C}$ ), and higher Chl concentrations $\left(>5 \mathrm{mg} \mathrm{m}^{-3}\right)$ in comparison to those observed in the nutrient-depleted region (Fig. 4a). Salinity maintains a lateral gradient across the region, with the highest salinity in the west near OSP ( $\sim 32.4$ PSU) and fresher water near shore in the east ( $<32$ PSU, Fig. $4 \mathrm{c})$. These observed patterns are replicated in the MOM6-COBALT model, including the east-west contrasts in surface nitrate, SST, SSS and Chl between the coastal region, the nitrate-depleted region and the subpolar gyre (Fig. 4). We note that consistent with the low nitrate climatological bias in the subtropical gyre mentioned above, the modeled surface nitrate concentration is lower in comparison to the Line $\mathrm{P}$ data, with maximum values rarely exceeding $8 \mu \mathrm{M}$ versus $15 \mu \mathrm{M}$ in the observations (Fig. 3a-b).

The Line P data support the model result and show an expansion of the nitrate-depleted region during the 2014-2015 "warm blob" (Fig. 4), leading to a westward shift of the $2 \mu \mathrm{M}$ boundary to $140^{\circ} \mathrm{W}$ in 2014 (vs a location of $130^{\circ} \mathrm{W}$ 
in the other years). In the model, this westward shift of the nitrate boundary is overestimated, extending past $140^{\circ} \mathrm{W}$. Thus, in both the observations and model this implies that nitrate becomes more depleted in the climatological HNLC Alaskan Gyre. The HNLC region can therefore be considered to contract while the nitrate-depleted region expands. We can see this explicitly in the model by examining the boundary between nitrate limitation and iron limitation (hatching, Fig. 6), the only two relevant nutrient limitations in this region. This boundary is strongly correlated to the $2 \mu \mathrm{M}$ nitrate boundary and moves seasonally accordingly. The NPTZ, then, is a region that seasonally switches between the two regimes. With the nitrate boundary shifting northward during warm events, this means that nitrate limitation is also expanded. Fig. 6 shows the climatological (gray) and MHW (purple) location of the limitation boundary in both winter (panels a \& c) and summer (panels b \& d). The region between these boundaries is then normally iron-limited, but becomes nitrate limited during warm events due to low nitrate concentrations. Thus. the limitation factor anomaly shifts northward with the seasonal migration of the nitrate boundary. Where the boundary reaches its northernmost and southernmost positions marks the edges of the strong anomaly.

\subsection{Reduced ecosystem production and export in NPTZ}

To understand the biological impacts of marine heat waves, we examine the composite of the nine simulated warm events. As expected from observations (Whitney 2015; Le et al. 2019), the model simulates the greatest biological anomalies in the NPTZ, including a negative Chl anomaly $\left(-0.03 \mathrm{mg} \mathrm{m}^{-3}\right.$, Fig. 6a) comparable with satellite observations (Fig. 1e). This Chl anomaly is spatially co-located with anomalously shallow winter mixed layers (-10 m, Fig. $6 \mathrm{~b})$ that reduced winter surface nitrate $(-2 \mu \mathrm{M}$, Fig. $6 \mathrm{c})$ and iron concentrations $(-0.1 \mu \mathrm{M}$, Fig. $6 \mathrm{~d})$. The low winter supply of nutrients during these events inhibits the annual production of both large $\left(-8 \mathrm{mmol} \mathrm{C} \mathrm{m}^{-2} \mathrm{Fig}\right.$. 6e) and small (-6 mmol $\mathrm{C} \mathrm{m}^{-2}$ Fig. 6f) phytoplankton inside the NPTZ. These negative anomalies in primary production propagate through the food web, leading to a drop in simulated zooplankton production of all three size classes (small, medium and large) and thus anomalously low total annual secondary production (-1 mmol m $\mathrm{m}^{-2} \mathrm{~d}^{-1}$, Fig. $\left.6 \mathrm{~g}\right)$. Similarly, particle export production, which includes zooplankton egestion and phytoplankton aggregation, also exhibits a negative production anomaly concentrated in the NPTZ $\left(-0.5 \mathrm{mmol} \mathrm{m}^{-2} \mathrm{~d}^{-1}\right.$, Fig. $\left.6 \mathrm{~h}\right)$.

245 While MHWs yield negative anomalies in annual primary and secondary production in the NPTZ (Fig. 6e-h), their effect varies seasonally and by plankton size class. Climatologically, the NPTZ in the model is characterized by a winter supply of nutrients supporting a modest spring bloom of large phytoplankton that peaks in April (13.5 mmol C $\mathrm{m}^{-2} \mathrm{~d}^{-1}$, Fig. S3e) followed by a much larger peak in small phytoplankton production in June $\left(47 \mathrm{mmol} \mathrm{C} \mathrm{m}^{-2} \mathrm{~d}^{-1}\right.$, Fig. S3f) that dominates total primary production. Seasonal Chl largely follows the large phytoplankton production due to 250 a $50 \%$ higher Chl:C ratio for large phytoplankton (0.018 vs. 0.012) in this region of the model (Geider et al. 1997; Stock et al. 2020). Thus, Chl peaks in April $\left(>0.6 \mathrm{mg} \mathrm{Chl} \mathrm{m}^{-3}\right)$ with more modest values during the small phytoplankton peak in June $\left(0.2 \mathrm{mg} \mathrm{Chl} \mathrm{m}^{-3}\right)$. Zooplankton production also follows a size-based progression. The production of medium-size zooplankton, the primary consumer of large phytoplankton, peaks first in May $\left(0.8 \mathrm{mmol} \mathrm{m}^{-2} \mathrm{~d}^{-1}\right.$, Fig. $\mathrm{S} 3 \mathrm{~g}$ ), followed by small zooplankton production which dominates total secondary production and peaks in May/June 
$255\left(1.4 \mathrm{mmol} \mathrm{m}^{-2} \mathrm{~d}^{-1}\right)$ as they feed on the small phytoplankton abundant at this time of year. Production of large zooplankton, which consume both large phytoplankton and medium zooplankton, is the smallest proportion of the total secondary production, peaking last in June $\left(0.2 \mathrm{mmol} \mathrm{m}^{-2} \mathrm{~d}^{-1}\right.$, Fig. S3f).

Marine heat waves modulate this climatological progression of the ecosystem in the NPTZ (Fig. 7). The model suggests that marine heat waves promote the growth of small phytoplankton and small to medium-sized zooplankton in early spring before dropping in summer-fall (Fig. 7e,f), due to the shallower mixed layer in winter and early spring (-10 m, Fig. $7 \mathrm{~b})$ that relieves light limitation and spurs small phytoplankton production (a positive production anomaly of $+2 \mathrm{mmol} \mathrm{m}^{-2} \mathrm{~d}^{-1}$, Fig. 7e). As the smaller size classes dominate the NPTZ, total zooplankton production also exhibits a positive anomaly through May $\left(+0.1 \mathrm{mmol} \mathrm{m}^{-2} \mathrm{~d}^{-1}\right.$, Fig. $\left.7 \mathrm{f}\right)$. Large phytoplankton, however, are impacted by stronger nutrient limitation during MHWs (Fig. 7h). While iron limitation, which dominates JanuaryApril, is only slightly more intense (limitation factor is lower by $<0.01$ ), the onset of nitrate limitation starts nearly a month earlier (early April vs late April) and the limitation factor is significantly lower (-0.06). Thus both size classes are limited by the reduced pool of nitrate (small phytoplankton are not simulated with iron limitation), with maximum negative anomalies in June $\left(-3 \mathrm{mmol} \mathrm{m} \mathrm{m}^{-2}\right.$ for small phytoplankton; $-2 \mathrm{mmol} \mathrm{m} \mathrm{d}^{-1} ;-1.5 \mathrm{mmol} \mathrm{C} \mathrm{m}^{-2} \mathrm{~d}^{-1}$ for total zooplankton production, Fig. 7e,f) when nitrate approaches depletion (Fig. S3).

Even with the small increase in winter and early spring small phytoplankton production, the annual mean surface Chl anomaly in the model is negative $\left(-0.03 \mathrm{mg} \mathrm{m}^{-3}\right.$, Fig. 6a) in agreement with satellite observations (Fig. 1e). This slight increase in small phytoplankton production in winter and early spring is only slightly apparent in both modeled and observed $\mathrm{Chl}$ (red and green lines, Fig. 7a) as the impact on surface $\mathrm{Chl}$ is small. This is again explained by the higher $\mathrm{Chl}$ C ratio of large phytoplankton compared to small phytoplankton which controls the overall response of Chl to marine heat waves in this region. Indeed, a $4 \%$ decrease in total phytoplankton production yields a $11 \%$ decline in $\mathrm{Chl}$, more closely resembling the decrease in large phytoplankton production (-12\%) than the decreased production of the more dominant but less Chl-dense small phytoplankton (-2\%). This model result is consistent with the decrease in Chl captured by satellite observations.

We examine the changes in phytoplankton assemblage across the NPTZ, using the normalized probability density functions of summer Chl concentrations (Fig. 9). In the NPTZ (Fig. 9c,d), the distribution of phytoplankton Chl concentrations for both size classes is bimodal, with one peak consistent with high Chl concentrations typically found in the Alaskan Gyre ( $\mathrm{Lg} \mathrm{Chl} \mathrm{peak} \mathrm{centered} \mathrm{at} 0.28 \mathrm{mg} \mathrm{m}^{-3}$; $\mathrm{Sm} \mathrm{Chl} \mathrm{peak} \mathrm{centered} \mathrm{at} 0.25 \mathrm{mg} \mathrm{m}^{-3}$, similar to the Alaskan gyre distribution shown in Fig. 9a-b), and one peak consistent with southern-like low chl concentrations typically found in the subtropical gyre $\left(\mathrm{Lg} \mathrm{Chl} \mathrm{peak} \mathrm{centered} \mathrm{at} 0.02 \mathrm{mg} \mathrm{m}^{-3} ; \mathrm{Sm} \mathrm{Chl} \mathrm{peak} \mathrm{centered} \mathrm{at} 0.06 \mathrm{mg} \mathrm{m}^{-3}\right.$, similar to the subtropical gyre distribution shown in Fig. 9e-f). During marine heat waves, the Chl distribution in the NPTZ exhibits a shift towards lower Chl concentrations, though the shift is greater for large phytoplankton (shift of $-0.05 \mathrm{mg}$ $\mathrm{m}^{-3}$ in the mean Chl concentration) than for smaller phytoplankton $\left(-0.02 \mathrm{mg} \mathrm{m}^{-3}\right.$ in the mean Chl concentration). The model suggests that climatologically, $31 \%$ of the NPTZ area has Chl concentrations $<0.15 \mathrm{mg} \mathrm{m}^{-3}$ for the large 
phytoplankton size-class, but that the proportion of the NPTZ with such low Chl concentrations increases to $41 \%$ during marine heat waves (Fig. 9, Fig. S6). Similarly, the proportion of the NPTZ with low small phytoplankton Chl concentrations $\left(\mathrm{Chl}<0.15 \mathrm{mg} \mathrm{m}^{-3}\right)$ increases from $28 \%$ in the climatological state to $38 \%$ during marine heat waves. In both cases, this shift is consistent with a decrease in the northern-like mode and an increase in the southern-like mode, and consistent with the decline in satellite Chl observed in this region.

\subsection{Modulated response in the Alaskan Gyre}

North of the NPTZ, in the AG, the biological impact of marine heatwaves is less prominent, with the model suggesting that decrease in annual large phytoplankton production is compensated by an increase in small phytoplankton production. Generally, the drivers of the ecosystem response to marine heat waves in the Alaskan gyre resemble the response simulated in the NPTZ (see Sect. 3.3) but the balance between the light-driven increase in small phytoplankton and nutrient-driven reduction in large phytoplankton is different. Specifically, we find that shallow mixed layers reduce light limitation during marine heat waves, and trigger an increase in spring small phytoplankton production $\left(+2 \mathrm{mmol} \mathrm{m}^{-3}\right.$, Fig. 8e) that exceeds the reduction in large phytoplankton production $\left(-1.5 \mathrm{mmol} \mathrm{m}^{-3}\right)$ caused by decreased nutrients early in the year (nitrate and iron, Fig. $8 \mathrm{c}, \mathrm{d}$ ). The negative $\mathrm{Chl}$ anomaly that starts in the spring (April) is due to the decreased large phytoplankton, which have a higher $\mathrm{Chl}: \mathrm{C}$, offset by the increased small phytoplankton production anomaly. Because anomalies are relatively small later in the year for both size classes (late spring to fall), the spring signal dominates the seasonal cycle and results in a slightly negative annually integrated Chl anomaly (-0.09 $\mathrm{mg} \mathrm{m}^{-3}$, Fig. 8a). Although satellite data show a greater compensation between a large negative spring anomaly and a positive summer anomaly than seen in the model, the simulated $\mathrm{Chl}$ response is consistent with the weak annually integrated negative $\mathrm{Chl}$ anomaly observed in satellite data $\left(-0.02 \mathrm{mg} \mathrm{m}^{-3}\right.$, green line).

315 The density distribution of summer Chl concentrations in the AG further supports this shifting of the phytoplankton assemblage toward small phytoplankton (Fig. 9a-b). For each phytoplankton size class there is one main mode (Large phytoplankton Chl peak centered at $0.29 \mathrm{mg} \mathrm{m}^{-3}$; small phytoplankton $\mathrm{Chl}$ peak centered at $0.25 \mathrm{mg} \mathrm{m}^{-3}$ ). The model suggests that climatologically, $42 \%$ of the AG area has large phytoplankton Chl concentrations $>0.4 \mathrm{mg} \mathrm{m}^{-3}$, but that this proportion drops to $35 \%$ during marine heat waves. This shift is associated with a reduction in the mean Chl concentration of the large phytoplankton fraction in the region $\left(-0.02 \mathrm{mg} \mathrm{m}^{-3}\right.$, Fig. 9). In contrast, mean small phytoplankton $\mathrm{Chl}$ concentrations in the AG remain virtually the same during marine heat waves. This result is supported by the observational OSP mixed-layer size-fractionated Chl $a$ measurements, which also displayed atypically low large phytoplankton $(>5 \mu \mathrm{m})$ Chl during the 2015 warm blob $\left(0.082 \mathrm{mg} \mathrm{m}^{-3}\right.$, star, Fig. 9a); in contrast, small phytoplankton Chl exhibits no significant change $\left(0.29 \mathrm{mg} \mathrm{m}^{-3}\right.$, star, Fig. $\left.9 \mathrm{~b}\right)$ during the same period compared to measurements from non-MHW years. These observed $\mathrm{Chl}$ values are lower than the simulated values and only sampled during the 2014-15 warm event. Yet, they are consistent with a transition of the phytoplankton assemblage toward the smaller size class in the AG region around OSP. 


\section{Discussion \& implications}

Previous studies have demonstrated there is a decrease in primary production in the NPTZ caused by reduced nitrate concentrations during MHWs. This decrease in nitrate concentrations was attributed to warmer upper ocean conditions, which drive a reduction in winter mixing (Amaya et al. 2021), and atmospheric blocking by an atmospheric ridge (Le et al. 2019), which decreases the wind-driven Ekman transport that carries nitrate from the northern Alaskan gyre southward, and otherwise supports up to $40 \%$ of the new production (Ayers and Lozier 2010). Our results agree with this literature, with both observations (Line P, Argo floats) and the MOM6-COBALT model indicating lower nitrate concentrations during MHW across the Alaskan gyre (which also has lower iron) and the NPTZ (Fig. 6c). Yet we show that $\mathrm{Chl}$ and biological production anomalies are restricted to the NPTZ only (Fig. 6a,e,f). Our results suggest, however, that nitrate concentrations alone cannot explain the confinement of the biological anomalies to the NPTZ, and that the interplay between nitrate and iron limitation, more specifically the position of the nitrate-to-iron limitation boundary (i.e., the boundary between the northern iron-limited regime and the southern nitrate limited regime), controls the location of the strongest MHW ecosystem anomalies.

345 We find that production anomalies associated with MHW are strongest in the NPTZ because the influence of reduced winter nitrate supply is greatest in the region that seasonally transitions from iron limitation in early spring to nitrate limitation in summer. In the subtropical gyre south of the NPTZ, nitrate is depleted year-round so that nitrate concentration cannot significantly decrease and impact biological production during MHWs. In the core of the Alaskan gyre, north of the NPTZ, annual production is iron-limited for large phytoplankton and mostly light-limited for small phytoplankton, thus changes in nitrate have only a limited effect. In the NPTZ, however, nitrate limitation starts earlier and is more intense during MHWs, with nitrate limitation factors that are about $20 \%$ smaller during spring and summer of MHWs than in the climatology (Fig. 8h). As a result, the NPTZ is the region where primary production is most impacted by the decrease in nitrate associated with MHWs.

\subsection{Collapse of observation-based production misattributed to marine heat wave}

The northward expansion of the nitrate-depleted region during MHW introduces biases in float-based estimates of net community production (NCP) and export. Floats in the vicinity of the NPTZ nitrate front can easily sample both the high nitrate and depleted nitrate regimes within a small spatial area ( $\sim 300 \mathrm{~km}$, Fig. 2$)$ and over the course of a few weeks or months. Float-based estimates of NCP (Appendix A) interpret nitrate changes sampled along the floats as temporal changes, leading to a misattribution of this spatial variability in nitrate to seasonal biological drawdown. In Bif et al. (2019b), NCP was calculated using the winter to summer difference in nitrate concentration measured by 6 Argo floats in the vicinity of OSP and the NPTZ between 2008 and 2018 (see details on method in SI, Fig. 10). From this data, they concluded that there was a collapse in ecosystem production during the warm blob in 2015. However, 
365 this dataset only includes one float sampling the area in 2015 (float 5904125), and the trajectory of that float incidentally sampled the low nitrate biome in winter before shifting to the higher nitrate HNLC region in summer (brown track, Fig. 2). The sampling of these two distinct biomes is supported by the at-depth (>100 m) measurements of temperature, nitrate and salinity, which indicate that this float crossed into a new water mass in early 2015 (Fig. 3). As a result, the winter-to-summer change in nitrate along the float was artificially small and the NCP calculation biased low in 2015.

We quantified the effect of the float shifting from the NPTZ to the Alaskan gyre on the NCP estimate by recomputing the NCP along the same float trajectories but sampling the climatological World Ocean Atlas nitrate concentrations instead of using the float nitrate data (Fig. 10). We find that most ( $>70 \%)$ of the NCP reduction derived from this float can be explained by the climatological nitrate field, and that the apparent ecosystem collapse in 2015 is in fact a feature of the float trajectory (red dashed line vs. black line). We performed a similar analysis using the MOM6COBALT model, first sampling the model climatological nitrate field and found the same result: the sampling trajectory of the float leads to an artificial NCP collapse in 2015 compared to other years that did not sample across this gradient. When taking into account model interannual variability, and hence the effect of the marine heatwave, we find an even stronger decline in NCP in 2015, suggesting that there is an NCP change caused by the "warm blob" itself. The model suggests, however, that only $30 \%$ of the decline in NCP can be attributed to the heat wave, while the remaining $70 \%$ is attributable to the sampling across the NPTZ nitrate front.

\subsection{Shift in phytoplankton assemblage due to contrasted size-class response}

Our results suggest that during MHWs, there is a shift in the phytoplankton community toward the smaller size class across both biomes, caused by the contrasted biological response across plankton size-classes. Large phytoplankton primarily respond to changes in nitrate and iron limitation. In the NPTZ, large phytoplankton are greatly impacted, with a $13 \%$ decrease in annual production (Fig. 6e, Fig. S2e) caused by stronger nutrient limitation during MHWs 390 (iron from January-April, then nitrate from June-Dec, Fig. 7h). In contrast, small phytoplankton in both regimes respond to both relieved light limitation (in spring) and enhanced nutrient limitation (in summer). Inside the NPTZ, where nitrate limitation is strongest, small phytoplankton production increases in spring, but is inhibited through summer until the mixed layer deepens in fall, resulting in a modest $4 \%$ decrease in annual small phytoplankton production. Thus despite decreased production of both size-classes during MHWs, the greater decrease in large phytoplankton production results in a lower large to small phytoplankton ratio (from $40 \%$ to $38 \%$ ) and small phytoplankton becoming a greater proportion of the total phytoplankton production.

In the Alaskan Gyre, the annual anomaly in large phytoplankton production is small, (-2 \%) driven by low production in spring when the iron supply is decreased (Fig. 7e). This is likely because the reduced winds that were shown to reduce nitrate supply during MHWs (Whitney 2015; Le et al. 2019) also impacted the iron supply. Unlike nitrate, however, iron returns to near-climatological levels by summer, which suggests that the sources of iron are decoupled 
from nitrate through the latter half of the year. As in the NPTZ, the spring small phytoplankton response is positive due to shallower mixed layers, however, in the nitrate-rich AG there is no summertime nutrient limitation of small phytoplankton and thus annual production is increased ( $+2 \%$, Fig. $6 f$, Fig. S2f). The decrease in annual large phytoplankton production with an increase in annual small phytoplankton production shifts the large to small ratio from $26 \%$ to $24 \%$, shifting total production toward the smaller size class.

Across both regions, this shift implies that during MHWs, there is a reduced proportion of large phytoplankton such as diatoms and dinoflagellates versus larger proportions of smaller groups such as cyanobacteria and nanoflagellates. Evidence of this shift has been observed in the AG during the "warm blob" (Peña et al. 2019) which found higher concentrations of cyanobacteria in the nitrate-depleted region of Line $\mathrm{P}$ and data presented in this paper, which show higher Chl $a$ concentrations in the smaller size classes at OSP (Sect. 3.3, 3.4). However, our work suggests this shift is more widespread, impacting both the AG and the NPTZ. Because diatoms and other large phytoplankton are known to support more productive food webs and more efficient biological carbon pumps (Boyd and Harrison 1999), their

415 decrease would likely substantially affect the marine ecosystem structure and reduce carbon export potential. This in turn, increases mortality risks for certain species, may promote geographical redistributions of fisheries, and creates challenging social and political environments stemming from increased economic tensions (Frölicher and Laufkötter 2018). Further, MHWs are expected to persist (Xu et al. 2021) and the atmospheric pressure systems associated with extreme events will increase in frequency (Giamalaki et al. 2021) thus we should anticipate this ecosystem shift during MHWs in the future.

\section{Appendix A.}

Argo NCP Calculation

To calculate NCP, it is assumed that new production is fueled by nitrate supplied from the deep ocean during winter mixing (Dugdale and Goering 1967). Thus, the temporal change in nitrate stock from the winter, i.e. when the mixed layer is deepest, to a given date must be due to net community production. This temporal change in nitrate is integrated over the top $75 \mathrm{~m}$ as follows:

$$
N C P=r_{C: N} \int_{0}^{75} N O_{3_{\text {winter }}}-N O_{3} d z
$$

Where $r_{C: N}$ is the Redfield ratio of carbon to nitrogen. This calculation assumes all changes in nitrate are due

430 to NCP, ignoring potential lateral and vertical contributions from physical transport. An integration depth of $75 \mathrm{~m}$ is selected to remain above the nitracline to limit the influence of transport, so that changes in nitrate above this depth can be largely attributed to biological processes. February was selected to be the winter month for each year as the mixed layer is often maximal between January and March; this simplification allows for a continuous time series to be calculated from February of each year. These choices are consistent with the previous study of Bif et al. (2019b).

\section{Author contribution}

AW and LR performed the model simulation and data analysis. AM provided OSP Chl $a$ measurements. AW and LR prepared the manuscript with contributions from AM. 


\section{Competing Interests}

The authors declare that they have no conflict of interest.

\section{Acknowledgements}

This study has been supported by the NASA ROSES 2018 EXPORTS award\# 80NSSC17K0555 and 80NSSC17K0552, the National Science Foundation (NSF) project "Eddy Effects on the Biological Carbon Pump" award\# 2023108, the Sloan Foundation, and the NSF Graduate Research Fellowship Program (NSF-GRFP). Funding that enabled AM participation on the Line P cruise in 2015 was provided by NSF award\# OCE1334935. The authors thank David Luet and Enhui Liao for their help and technical support in developing and running the MOM6-COBALT ocean simulation used in this study. The authors also thank the Geophysical Fluid Dynamical Laboratory and the MOM6 ocean modeling team for developing, maintaining and making the MOM6 ocean model publicly available on GitHub (https://github.com/NOAA-GFDL/MOM6-examples).

\section{References}

Adcroft, A., Anderson, W., Balaji, V., Blanton, C., Bushuk, M., Dufour, C. O., Dunne, J. P., Griffies, S. M., Hallberg, R., Harrison, M. J., Held, I. M., Jansen, M. F., John, J. G., Krasting, J. P., Langenhorst, A. R., Legg, S., Liang, Z., McHugh, C., Radhakrishnan, A., Reichl, B. G., Rosati, T., Samuels, B. L., Shao, A., Stouffer, R., Winton, M., Wittenberg, A. T., Xiang, B., Zadeh, N., and Zhang, R.: The GFDL Global Ocean and Sea Ice Model OM4.0: Model Description and Simulation Features, 11, 3167-3211, https://doi.org/10.1029/2019MS001726, 2019.

Amaya, D. J., Alexander, M. A., Capotondi, A., Deser, C., Karnauskas, K. B., Miller, A. J., and Mantua, N. J.: Are Long-Term Changes in Mixed Layer Depth Influencing North Pacific Marine Heatwaves?, 102, S59-S66, https://doi.org/10.1175/BAMS-D-20-0144.1, 2021.

Ayers, J. M. and Lozier, M. S.: Physical controls on the seasonal migration of the North Pacific transition zone chlorophyll front, 115, https://doi.org/10.1029/2009JC005596, 2010.

Bif, M. B. and Hansell, D. A.: Seasonality of Dissolved Organic Carbon in the Upper Northeast Pacific Ocean, https://doi.org/10.1029/2018GB006152, 2019a.

Bif, M. B., Siqueira, L., and Hansell, D. A.: Warm Events Induce Loss of Resilience in Organic Carbon Production in the Northeast Pacific Ocean, 0, https://doi.org/10.1029/2019GB006327, 2019b.

Bond, N. A., Cronin, M. F., Freeland, H., and Mantua, N.: Causes and impacts of the 2014 warm anomaly in the NE Pacific, 42, 3414-3420, https://doi.org/10.1002/2015GL063306, 2015.

Boyd, P. and Harrison, P. J.: Phytoplankton dynamics in the NE subarctic Pacific, Deep Sea Research Part II: Topical Studies in Oceanography, 46, 2405-2432, https://doi.org/10.1016/S0967-0645(99)00069-7, 1999.

Boyer, T. P., Antonov, J. I., Baranova, O. K., Garcia, H. E., Johnson, D. R., Mishonov, A. V., O’Brien, T. D., Seidov, D., I. (Igor), S., Zweng, M. M., Paver, C. R., Locarnini, R. A., Reagan, J. R., Coleman, C., and Grodsky, A.: World ocean database 2013., https://doi.org/10.7289/V5NZ85MT, 2013. 
Boyin Huang, Viva F. Banzon, Eric Freeman, Jay Lawrimore, Wei Liu, Thomas C. Peterson, Thomas M. Smith, Peter W. Thorne, Scott D. Woodruff, and Huai-Min Zhang: Extended Reconstructed Sea Surface Temperature (ERSST), Version 4. NOAA National Centers for Environmental Information. doi:10.7289/V5KD1VVF, 2015.

Brand, L. E., Guillard, R. R. L., and Murphy, L. S.: A method for the rapid and precise determination of acclimated phytoplankton reproduction rates, Journal of Plankton Research, 3, 193-201, https://doi.org/10.1093/plankt/3.2.193, 1981.

Buesseler, K. O.: The decoupling of production and particulate export in the surface ocean, 12, 297-310, https://doi.org/10.1029/97GB03366, 1998.

Di Lorenzo, E. and Mantua, N.: Multi-year persistence of the 2014/15 North Pacific marine heatwave, 6, 1042 1047, https://doi.org/10.1038/nclimate3082, 2016.

Dugdale, R. C. and Goering, J. J.: Uptake of New and Regenerated Forms of Nitrogen in Primary Productivity1, 12, 196-206, https://doi.org/10.4319/1o.1967.12.2.0196, 1967.

Dunne, J. P., John, J. G., Adcroft, A. J., Griffies, S. M., Hallberg, R. W., Shevliakova, E., Stouffer, R. J., Cooke, W., Dunne, K. A., Harrison, M. J., Krasting, J. P., Malyshev, S. L., Milly, P. C. D., Phillipps, P. J., Sentman, L. T., Samuels, B. L., Spelman, M. J., Winton, M., Wittenberg, A. T., and Zadeh, N.: GFDL's ESM2 Global Coupled Climate-Carbon Earth System Models. Part I: Physical Formulation and Baseline Simulation Characteristics, J. Climate, 25, 6646-6665, https://doi.org/10.1175/JCLI-D-11-00560.1, 2012.

Freeland, H. and Whitney, F.: Unusual warming in the Gulf of Alaska, 22, 51-52, 2014.

Frölicher, T. L. and Laufkötter, C.: Emerging risks from marine heat waves, Nat Commun, 9, 650, https://doi.org/10.1038/s41467-018-03163-6, 2018.

Geider, R., MacIntyre, H., and Kana, T.: Dynamic model of phytoplankton growth and acclimation:responses of the balanced growth rate and the chlorophyll a:carbon ratio to light, nutrient-limitation and temperature, Mar. Ecol. Prog. Ser., 148, 187-200, https://doi.org/10.3354/meps148187, 1997.

Giamalaki, K., Beaulieu, C., Henson, S. A., Martin, A. P., Kassem, H., and Faranda, D.: Future intensification of extreme Aleutian low events and their climate impacts, Sci Rep, 11, 18395, https://doi.org/10.1038/s41598021-97615-7, 2021.

Khatiwala, S., Tanhua, T., Mikaloff Fletcher, S., Gerber, M., Doney, S. C., Graven, H. D., Gruber, N., McKinley, G. A., Murata, A., Ríos, A. F., and Sabine, C. L.: Global ocean storage of anthropogenic carbon, 10, 21692191, https://doi.org/10.5194/bg-10-2169-2013, 2013.

Kirk, J. T. O.: Ch9 - Light capture by aquatic plants, in: Light and photosynthesis in aquatic ecosystems, Cambridge University Press, Cambridge, 252-270, https://doi.org/10.1017/CBO9780511623370, 1994.

Le, C., Wu, S., Hu, C., Beck, M. W., and Yang, X.: Phytoplankton decline in the eastern North Pacific transition zone associated with atmospheric blocking, 25, 3485-3493, https://doi.org/10.1111/gcb.14737, 2019.

Liao, E., Resplandy, L., Liu, J., and Bowman, K. W.: Amplification of the Ocean Carbon Sink During El Niños: Role of Poleward Ekman Transport and Influence on Atmospheric CO2, 34, e2020GB006574, https://doi.org/10.1029/2020GB006574, 2020.

Munk, W. and Riley, G.: Absorption of nutrients by aquatic plants, 11, 121-152, 1952.

Olsen, A., Key, R. M., van Heuven, S., Lauvset, S. K., Velo, A., Lin, X., Schirnick, C., Kozyr, A., Tanhua, T., Hoppema, M., Jutterström, S., Steinfeldt, R., Jeansson, E., Ishii, M., Pérez, F. F., and Suzuki, T.: The 
Global Ocean Data Analysis Project version 2 (GLODAPv2) - an internally consistent data product for the world ocean, 8, 297-323, https://doi.org/10.5194/essd-8-297-2016, 2016.

Peña, M. A., Nemcek, N., and Robert, M.: Phytoplankton responses to the 2014-2016 warming anomaly in the northeast subarctic Pacific Ocean, 64, 515-525, https://doi.org/10.1002/lno.11056, 2019.

Seitzinger, S. P., Mayorga, E., Bouwman, A. F., Kroeze, C., Beusen, A. H. W., Billen, G., Drecht, G. V., Dumont, E., Fekete, B. M., Garnier, J., and Harrison, J. A.: Global river nutrient export: A scenario analysis of past and future trends, 24, https://doi.org/10.1029/2009GB003587, 2010.

Stock, C. A., Dunne, J. P., and John, J. G.: Global-scale carbon and energy flows through the marine planktonic food web: An analysis with a coupled physical-biological model, Progress in Oceanography, 120, 1-28, https://doi.org/10.1016/j.pocean.2013.07.001, 2014.

Stock, C. A., Dunne, J. P., Fan, S., Ginoux, P., John, J., Krasting, J. P., Laufkötter, C., Paulot, F., and Zadeh, N.: Ocean Biogeochemistry in GFDL's Earth System Model 4.1 and Its Response to Increasing Atmospheric CO2, 12, e2019MS002043, https://doi.org/10.1029/2019MS002043, 2020.

Suryan, R. M., Arimitsu, M. L., Coletti, H. A., Hopcroft, R. R., Lindeberg, M. R., Barbeaux, S. J., Batten, S. D., Burt, W. J., Bishop, M. A., Bodkin, J. L., Brenner, R., Campbell, R. W., Cushing, D. A., Danielson, S. L., Dorn, M. W., Drummond, B., Esler, D., Gelatt, T., Hanselman, D. H., Hatch, S. A., Haught, S., Holderied, K., Iken, K., Irons, D. B., Kettle, A. B., Kimmel, D. G., Konar, B., Kuletz, K. J., Laurel, B. J., Maniscalco, J. M., Matkin, C., McKinstry, C. A. E., Monson, D. H., Moran, J. R., Olsen, D., Palsson, W. A., Pegau, W. S., Piatt, J. F., Rogers, L. A., Rojek, N. A., Schaefer, A., Spies, I. B., Straley, J. M., Strom, S. L., Sweeney, K. L., Szymkowiak, M., Weitzman, B. P., Yasumiishi, E. M., and Zador, S. G.: Ecosystem response persists after a prolonged marine heatwave, Sci Rep, 11, 6235, https://doi.org/10.1038/s41598-021-83818$5,2021$.

Tsujino, H., Urakawa, S., Nakano, H., Small, R. J., Kim, W. M., Yeager, S. G., Danabasoglu, G., Suzuki, T., Bamber, J. L., Bentsen, M., Böning, C. W., Bozec, A., Chassignet, E. P., Curchitser, E., Boeira Dias, F., Durack, P. J., Griffies, S. M., Harada, Y., Ilicak, M., Josey, S. A., Kobayashi, C., Kobayashi, S., Komuro, Y., Large, W. G., Le Sommer, J., Marsland, S. J., Masina, S., Scheinert, M., Tomita, H., Valdivieso, M., and Yamazaki, D.: JRA-55 based surface dataset for driving ocean-sea-ice models (JRA55-do), Ocean Modelling, 130, 79-139, https://doi.org/10.1016/j.ocemod.2018.07.002, 2018.

Whitney, F. A.: Anomalous winter winds decrease 2014 transition zone productivity in the NE Pacific, 42, 428-431, https://doi.org/10.1002/2014GL062634, 2015.

Xu, T., Newman, M., Capotondi, A., and Lorenzo, E. D.: The Continuum of Northeast Pacific Marine Heatwaves and Their Relationship to the Tropical Pacific, 48, 2020GL090661, https://doi.org/10.1029/2020GL090661, 2021. 
Figures


Fig 01. (a) Observations of sea surface temperature anomalies (SSTa) from extended reconstructed sea surface temperature data (ERSST, orange) compared to MOM6-COBALT simulated SSTa (blue) averaged for 19582020 across $35^{\circ}$ to $46^{\circ} \mathrm{N}$ and $150^{\circ}$ to $135^{\circ} \mathrm{W}$ (see Methods). (b) Observed surface Chl anomaly (GlobColour, orange) and model (blue) for 1997-2020 period. Marine heat waves (MHWs) are highlighted in gray. (c) Observational and (d) modeled spatial pattern of the SSTa composite of the 9 MWHs overlaid with SST climatology (gray contours). (e)

Observational and (f) modeled spatial pattern of the Chl anomalies composite of the last 4 warm events for which observational $\mathrm{Chl}$ data are available overlaid with the surface Chl climatology (gray contours). Yellow circles indicate every fourth Line P station and the black star denotes ocean station papa (OSP, 50.1 $\left.{ }^{\circ} \mathrm{N}, 144.9^{\circ} \mathrm{W}\right)$. Trajectories of Argo floats in the region for 2008-2018 are shown in gray. The boxes delimit the North Pacific Transition Zone (NPTZ in black, $39^{\circ}-45^{\circ} \mathrm{N}$ and $160^{\circ}-135^{\circ} \mathrm{W}$ ) and the Alaskan Gyre ( $\mathrm{AG}$ in red, $48^{\circ}-54^{\circ} \mathrm{N}$ and $160^{\circ}-145^{\circ} \mathrm{W}$ ). 


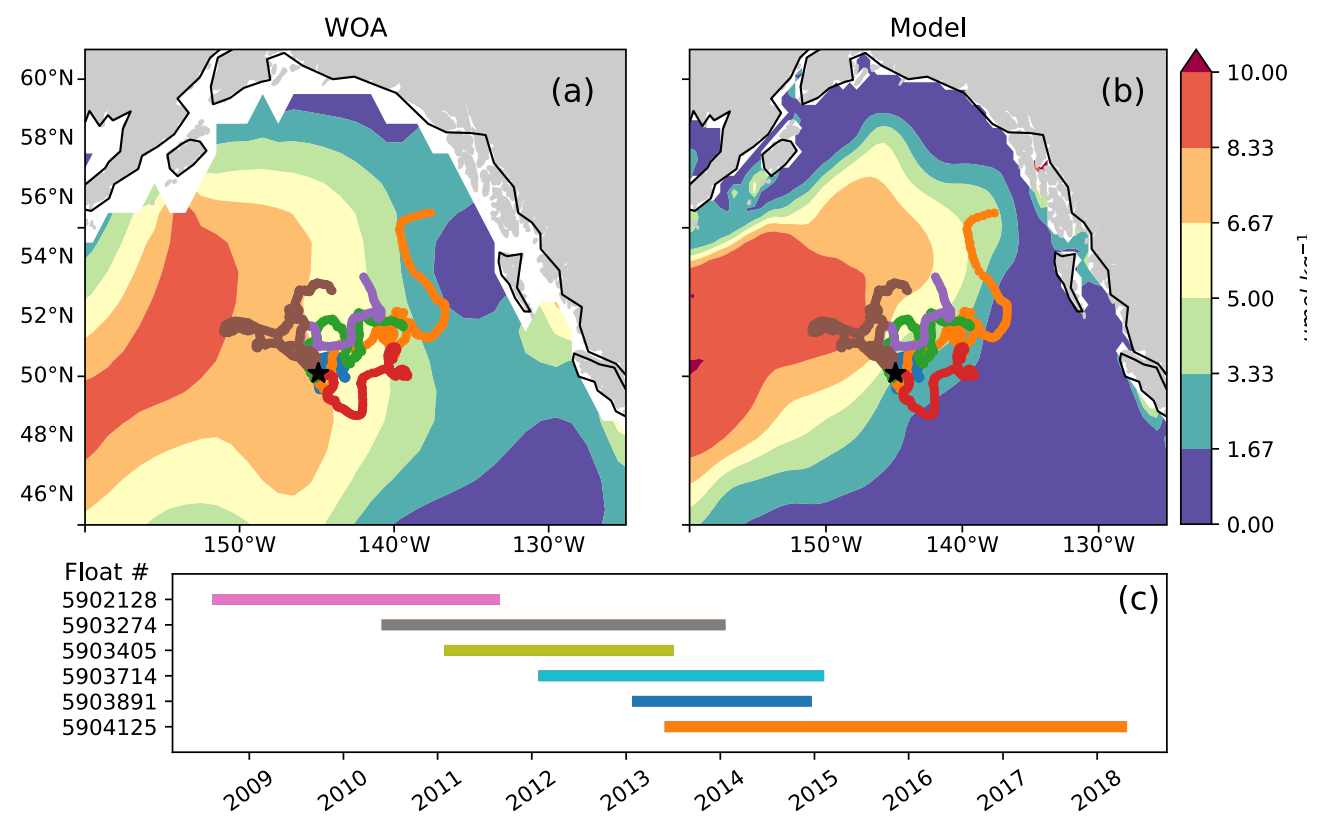

Fig 02. Argo float trajectories overlaid on late summer (August) surface nitrate concentrations in (a) the World Ocean Atlas, and (b) MOM6-COBALT. The sampling period of each float is shown in (c). Note that float 5904125 (brown) travels west across the east-west nitrate gradient, and is the only float sampling the region between 2015 and 2018. 

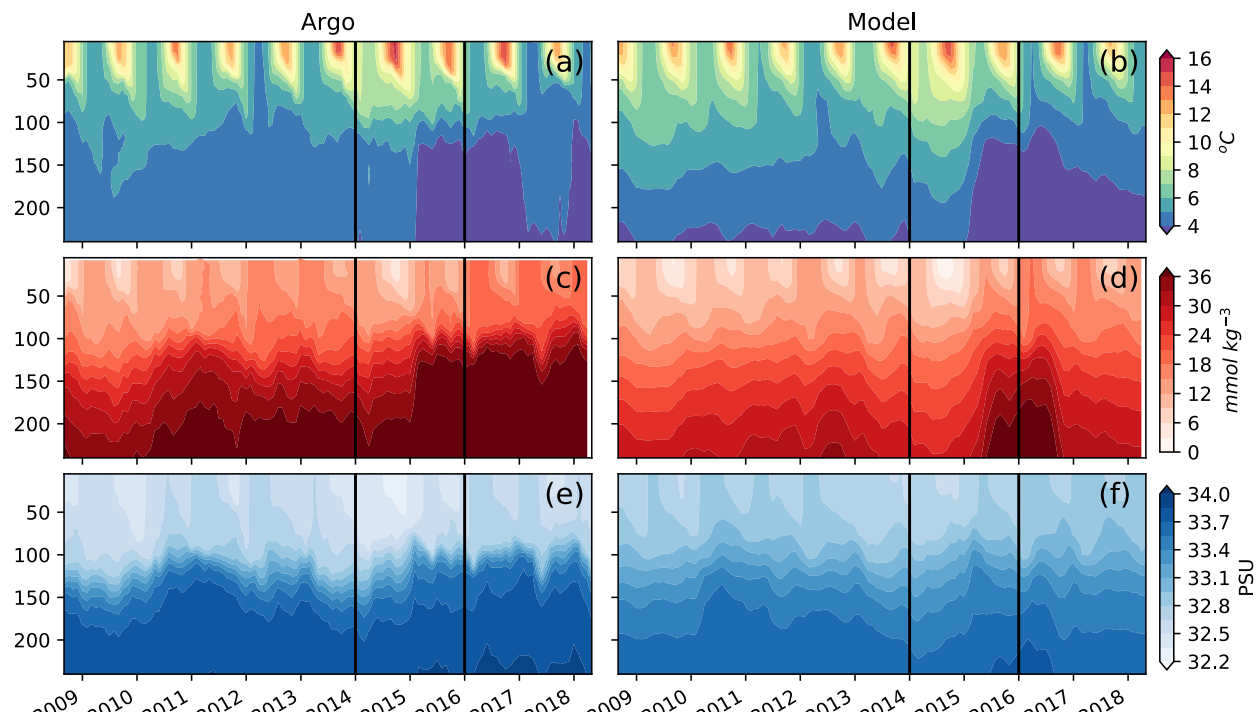

Fig 03. Comparison of observations from Argo floats shown in Fig $2(\mathrm{a}-\mathrm{c})$ and sampled along their trajectories in MOM6-COBALT $(\mathrm{d}-\mathrm{f})$ for temperature $(\mathrm{a}, \mathrm{d})$, nitrate concentration $(\mathrm{b}, \mathrm{e})$ and salinity $(\mathrm{c}, \mathrm{f})$. The "warm blob" period is delimited by January 2014 and December 2015 with vertical black lines. 


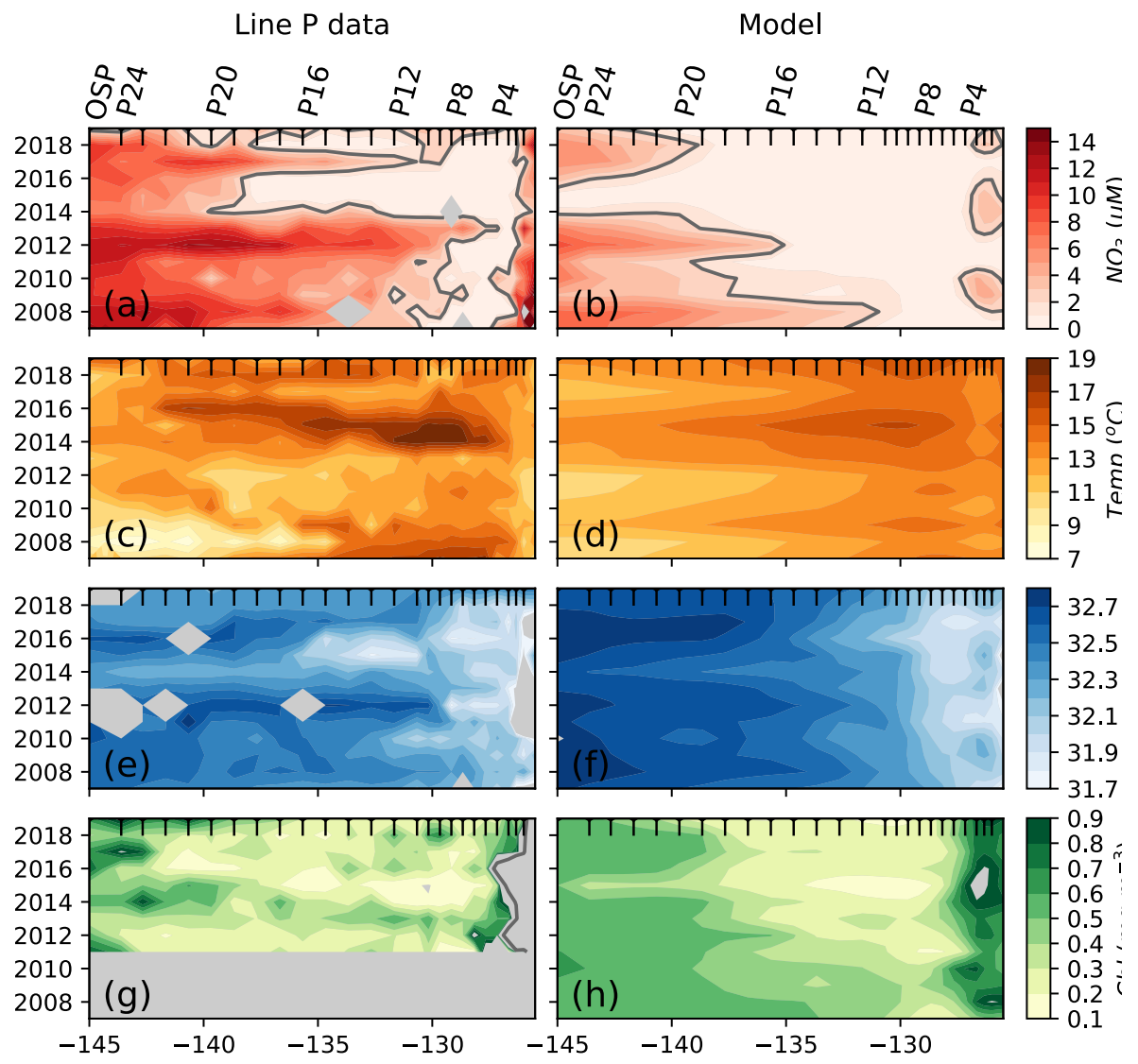

Fig 04. Impact of the 2014-2015 "warm blob" along Line P. a) Surface nitrate concentration averaged across summer cruises (generally one in June, one in August) along Line P stations P1 to P26 (OSP). b) Same as panel a, but sampled in the model at the station locations and averaged from June through August. The $2 \mu \mathrm{M}$ nitrate boundary is shown as a solid gray line. Other panels are the same as $(a, b)$ for observed and modeled $(c, d)$ sea surface temperature, $(\mathrm{e}, \mathrm{f})$ sea surface salinity and $(\mathrm{g}, \mathrm{h})$ surface $\mathrm{Chl}$. Gray shading indicates lack of data. Black x-axis ticks indicate station positions. See Fig 2 for Line P station map. 


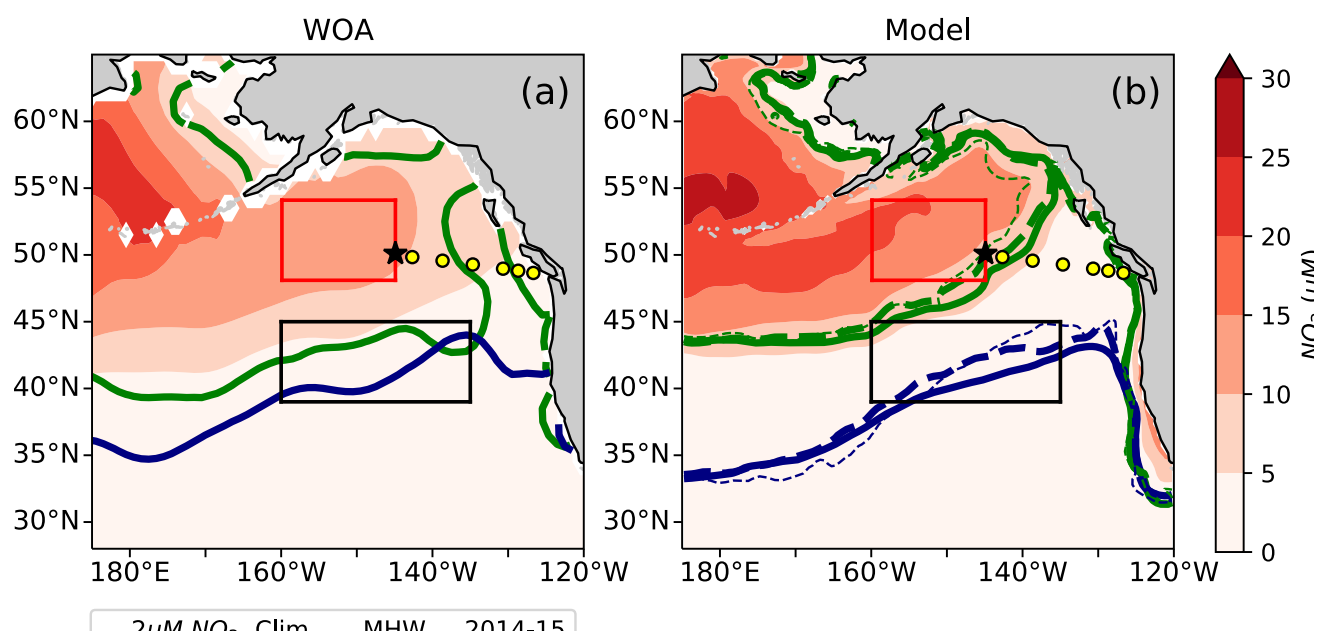

Fig 05. Annual mean surface nitrate concentrations in (a) world ocean atlas observations (WOA, Boyer, 2018) and (b) MOM6-COBALT model. The seasonal location of the $2 \mu \mathrm{M}$ surface nitrate contour in February (blue) and

585 September (green) are indicated for the climatology (solid lines), the warm events composite (dashed lines) and the 2014-2015 "warm blob" (thin dashed lines). The nitrate-depleted region south of the $2 \mu \mathrm{M}$ boundary extends further north in both winter and summer during warm events. Line P, OSP and boxes for AG and NPTZ are shown as described in Fig 1. 

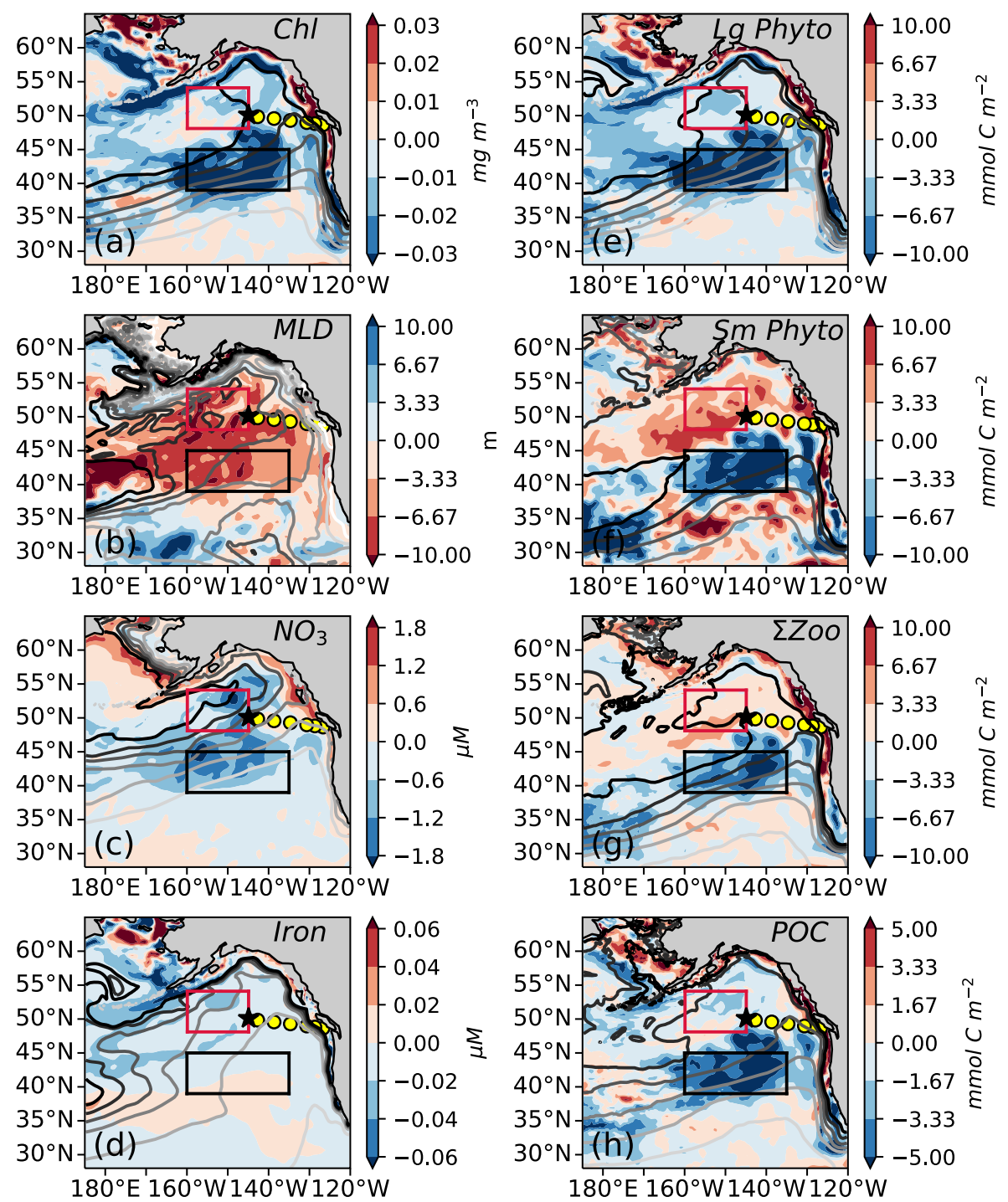

590 Fig 06. Modeled composite of the 9 marine heatwave anomalies (1958-2020) for (a) monthly surface Chl concentration, (b) winter (Jan-Mar) MLD, (c) winter surface nitrate concentration, (d) winter surface iron concentration, (e) annual depth-integrated large phytoplankton production (0-100 m), (f) annual depth-integrated small phytoplankton production $(0-100 \mathrm{~m}),(\mathrm{g})$ annual depth-integrated sum of large, medium and small zooplankton production $(0-100 \mathrm{~m})$, (h) annual POC export at $100 \mathrm{~m}$ depth. Each field is overlaid with contours of the mean climatological state with darker lines indicating higher values (see mean state maps in Fig S2). Line P, OSP and boxes for AG and NPTZ are shown as described in Fig 1. 

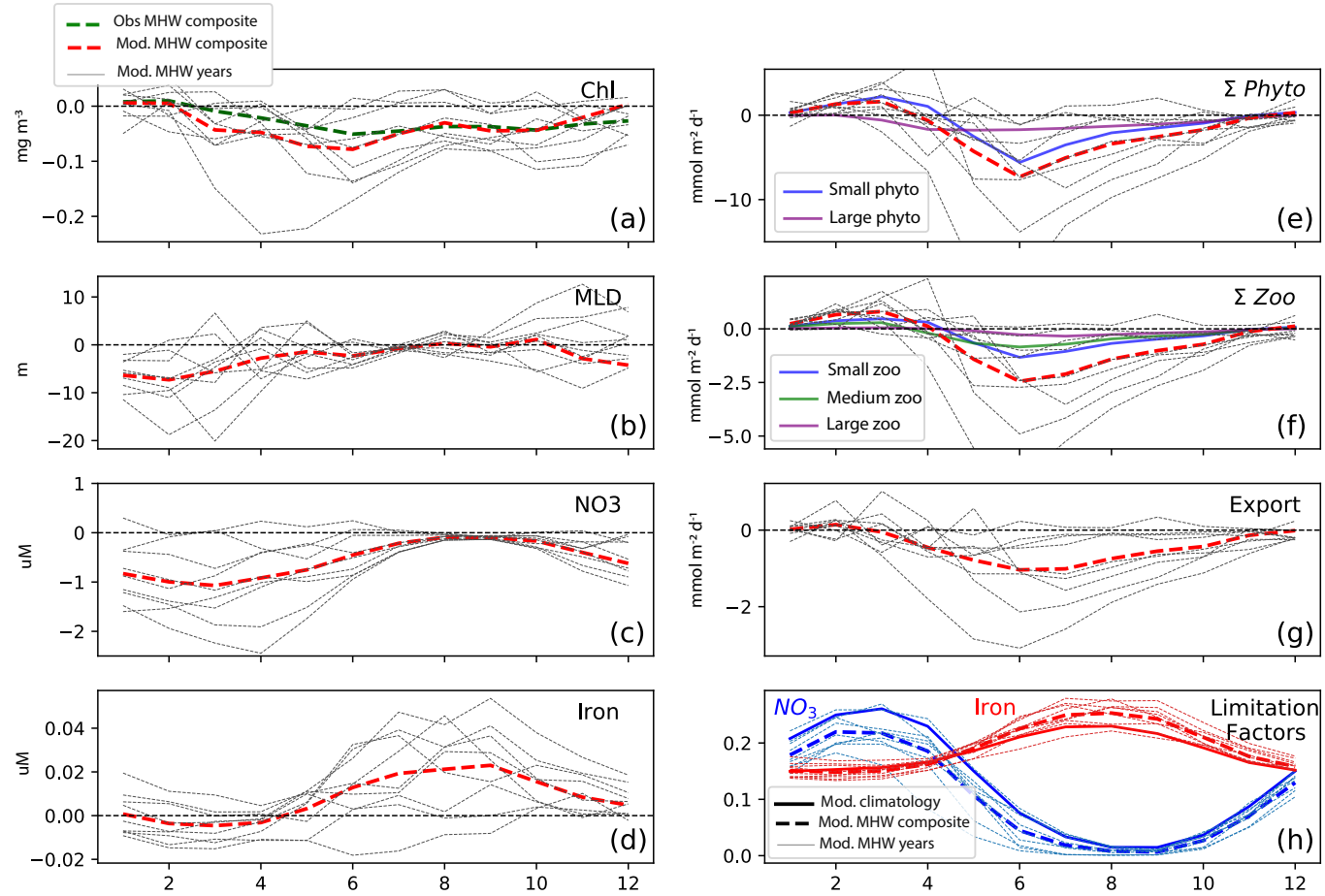

Fig 07. Seasonal response to MHWs in the NPTZ (black box shown in Fig. 1, 38 $-48^{\circ} \mathrm{N}$ and $165^{\circ}-135^{\circ} \mathrm{W}$ ).

Composite anomalies of the 9-event MHWs for: (a) modeled surface Chl (red) and observed surface Chl (GlobColour, green), (b) modeled mixed layer depth, (c) surface nitrate concentration, (d) surface iron concentration, (e) depth integrated phytoplankton production (0-100 m) with individual size classes (small in blue, large in purple), (f) depth integrated zooplankton production $(0-100 \mathrm{~m})$ with individual size classes (small in blue, medium in green, large in purple), (h) particulate export production at $100 \mathrm{~m}$ depth and (h) large phytoplankton nutrient limitation factors for iron (red) and nitrate (blue) for the mean climatological state (solid line) and the MHW composite (dashed lines). Across all panels, thin lines show anomalies for the 9 individual MHW years. 

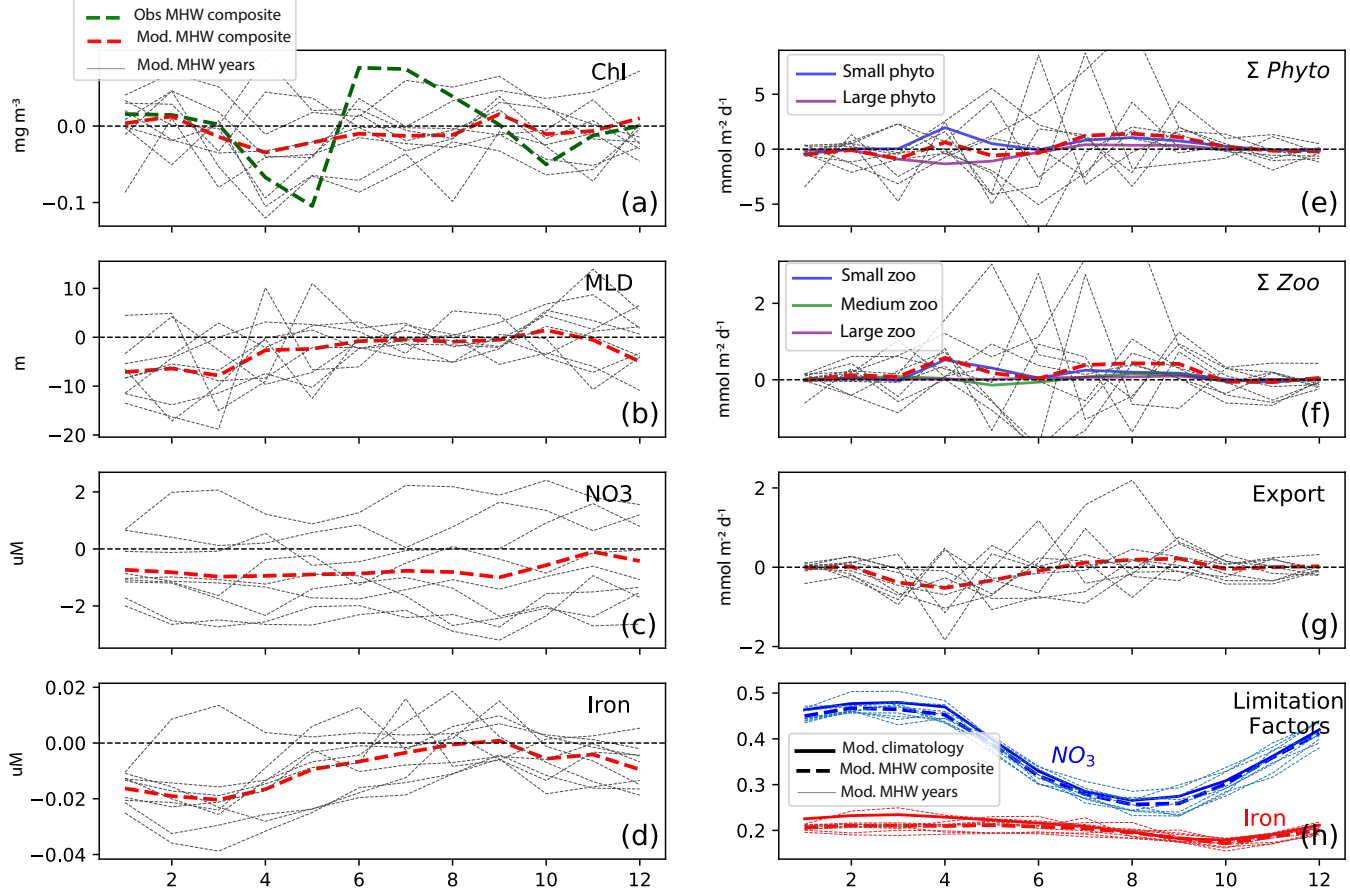

Fig 08. Response to marine heat waves in the AG (red box shown in Fig 7, 48॰54N and $160^{\circ}-145^{\circ} \mathrm{W}$ ). Same as Fig.
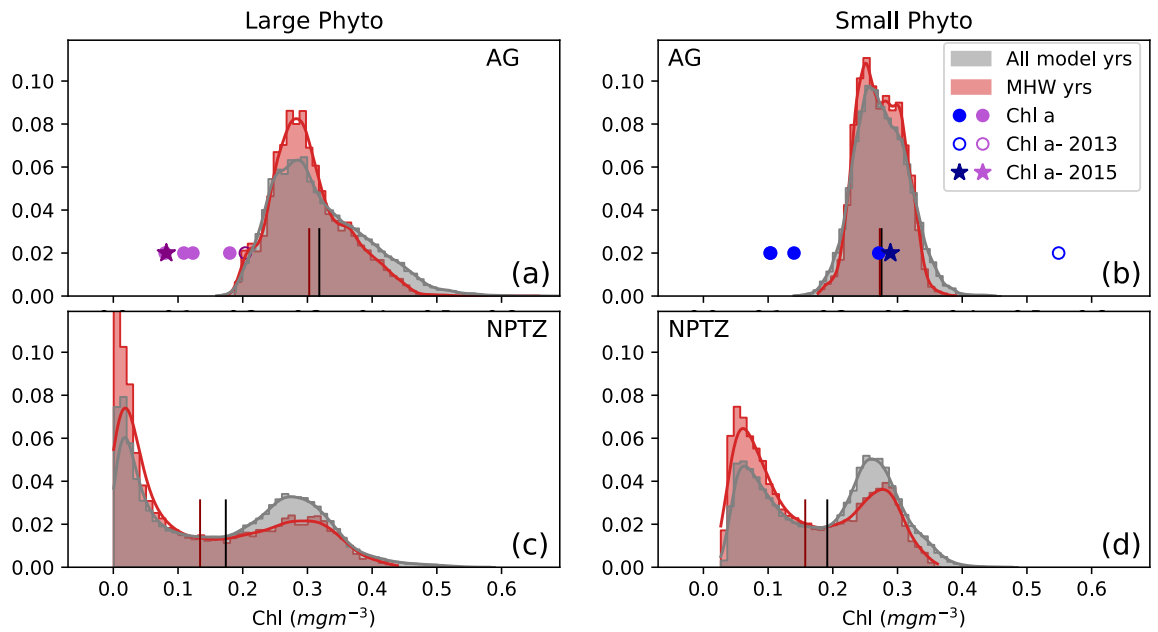
Fig 09. Observed and modeled summer (May-Aug) $\mathrm{Chl}\left(\mathrm{mg} \mathrm{m}^{-3}\right)$ contained in the large (left) and small (right) phytoplankton size fraction in two regions: (a,b) Alaskan Gyre and (c,d) North Pacific Transition Zone. Model data are shown as normalized probability density functions for the MHW composite (red) and the climatology (gray). Observations from the six OSP cruises in the Alaskan Gyre are shown as symbols on panels $\mathrm{a}-\mathrm{b}$ (data for years 2000, 2001, 2008, 2013, 2015, and 2018, see method Section 2.4). Data from the 2015 warm blob (star) and 2013 volcanic eruption (hollow circle) are distinguished from other data (filled circles).

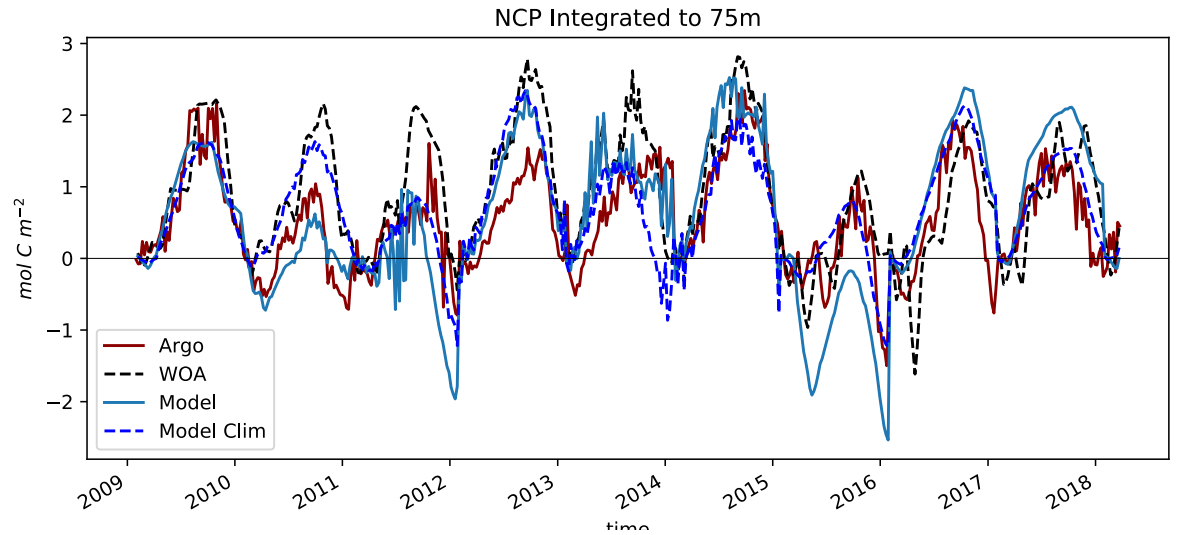

Fig 10. Net community production (NCP) calculated as nitrate drawdown from winter supply (February) using Argo float data (dark red), and along the float trajectories using the WOA nitrate climatology (black dashed), the interannual results from MOM6-COBALT (light blue) and the MOM6-COBALT climatology (blue dashed). 